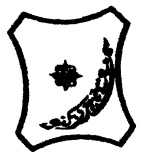

Bayero Journal of Pure and Applied Sciences, 11(1): 15 - 19

Received: November, 2017

Accepted: February, 2018

ISSN $2006-6996$

\title{
EVALUATION OF QUALITATIVE PHYTOCHEMICALS AND ANTIFUNGAL ACTIVITY OF AQUEOUS LEAF EXTRACT OF Senna tora ON DOWNY MILDEW OF CABBAGE
}

\author{
${ }^{* 1}$ Zakari S.M., ${ }^{2}$ Aliko, A.A. ${ }^{3}$ Haruna, H. and ${ }^{4}$ Muazu. A \\ 1,2,3,4 Department of Plant Biology Bayero University, Kano \\ *corresponding author: smzakari.bot@buk.edu.ng
}

\section{ABSTRACT}

This study was embarked upon to evaluate the efficacy of aqueous extracts of Senna tora leaf against Perenospora parasitica, causing downy mildew on cabbage. Phytochemical analysis of the leaf extracts revealed the presence of some secondary metabolites (Tannins, Saponins, Flavonoid, Glycosides, Alkaloids, Phenolic compounds and Carbohydrates) which have been reported to have antimicrobial effects. Assays were performed using extract concentrations of 1000, 500, 250, 125 $\mathrm{mg} / \mathrm{ml}$ by agar well diffusion technique. Results obtained, revealed a significant difference in diameter of mycelial zone of inhibition between the concentrations. Highest zone of inhibition was recorded at 1000 and $500 \mathrm{mg} / \mathrm{ml}(20$ and $15 \mathrm{~mm}$ ) respectively. Minimum Inhibitory Concentration (MIC) and Minimum Fungicidal Concentration (MFC) were determined and recorded at $250 \mathrm{mg} / \mathrm{ml}$. The antifungal screening revealed that the extract exhibited inhibitory activities at varying concentrations against the downy mildew pathogen. These activities observed could be attributed to the presence of active metabolites contained in the extract.

Keywords: Aqueous leaf extract, Downy mildew, Perenospora parasitica and Senna tora,

\section{INTRODUCTION}

The development of resistance to current antibiotics by disease causing microbes has reinforced research for discovery of new ones (Kunle and Eghareva, 2009). Continuous and overuse of synthetic antibiotics often produce tolerance in human and create resistance in microbes for a particular antibiotic. Current trends in drug development process are focused on natural sources, especially source of plant origin due to some proven correlation between the folk medicinal uses of some of these plants to biological activity. Therefore, the use of plant materials to prevent and treat infectious diseases successfully over the years has continued to attract the attention of scientists worldwide (Kunle and Egharevba, 2009).

Medicinal plants are gifts of nature to cure limitless number of diseases. The abundance of plants on the earth surface has led to an increasing interest in the investigation of different extracts obtained from the traditional medicinal plants as potential sources of new antimicrobial agents (Bonjar and Farrokhi, 2004). In recent years, there has been a gradual revival of interest concerning the use of medicinal and aromatic plants in developed as well as in developing countries in utilization to develop antimicrobial drugs, because plant- drive drugs have been reported to be safe and without side effects (Rai et al., 2003).

Senna tora L. (leguminosae) is widely distributed in tropical and Asian countries. The seeds are reputed in Chinese medicine as vision improving, antiasthenic, asperient, and diuretic agents. Senna tora have shown to possess various biological and pharmacological activities including antihepatotoxic, antiallergic, antimutagenic, antifungal, radical scavenging, and antimicrobial (Maity et al., 1998).
The leaves of Senna tora are used as laxative in the form of decoction. Both leaves and seeds constitute a valuable remedy in skin diseases, chiefly for ringworms and itch. In china the seeds are used externally for all sorts of eye diseases. In indo-china, the pods are used in dysentery and diseases of eye. In Nigeria, the leaves are used as mild laxative. The weed is used in various gold coast medicines, chiefly as purgative. In Madagascar and La reunion, the root is considered bitter, tonic, stomachic. The leaves are used as an anti-periodic, asperients, anthelmintic they are given to children with intestinal wounds. The plant and seeds are edible. The edible part of the plant varies from 30-40 percent. Young leaves can be cooked as vegetables while the roosted seeds are a good substitute for coffee. It is used as a natural pesticide in organic farms and its powder is most commonly used in the pet food industry. Alternatively, its mixed with guar gum for use in mining and other industrial applications (Benzie and Strain, 1996).

The aim of this study was to study the qualitative phytochemical contents and antifungal activity of aqueous leaf extract of Senna tora on downy mildew of cabbage

\section{MATERIALS AND METHODS}

Collection and Identification of Plant Material The leaves of Senna tora were collected randomly from Bayero University Kano old campus. The plant was identified and authenticated in the herbarium unit of Department of Plant Biology BUK with accession number BUKHAN 0307.

Preparation of the Leaf Extracts

The leaves were air dried at room temperature and grounded into powder using wooden pestle and mortar. The powdered plant material was stored in an 15 air tight container prior to extraction. 
Two hundred grams of the powdered leaf material was soaked in distilled water $(200 \mathrm{~g} / 1.5 \mathrm{~L})$ and the extract decanted at an interval of 24 hours. The filtrate was then evaporated to dryness in a water bath at $40^{\circ} \mathrm{C}$ giving a dark green solid with a yield of $13.2 \mathrm{~g}$ (Palanichmy and Nagarajan, 1990).

\section{Phytochemical Analysis}

Chemical tests for the screening and identification of bioactive chemical constituents in the leaf extract of Senna tora was carried out in extracts using the standard procedures as described by Harbone (1973), Trease and Evans(1989), and Sofowara (1993).

Test for Tannins

Few drops of $0.1 \%$ of $\mathrm{FeCl}_{3}$ were added to $0.01 \mathrm{~g}$ of the aqueous extract and boiled in $20 \mathrm{ml}$ of water in a boiling tube. Formation of brownish green or a blue black colouration indicated the presence of tannins.

\section{Test for Saponins}

The aqueous extract $(0.01 \mathrm{~g})$ was boiled in $20 \mathrm{ml}$ of distilled water in a water bath. Then it was mixed with $5 \mathrm{ml}$ of distilled water and it was shaken well. Stable persistent froth indicated the presence of saponins.

\section{Test for Flavonoid}

A few drops of $1 \% \mathrm{NH}_{3}$ solution was added to the aqueous extract of the plant sample in a test tube. A yellow coloration is observed if the flavonoid compounds are present.

\section{Test for Glycosides}

The aqueous extract $(0.01 \mathrm{~g})$ was dissolved in $2 \mathrm{ml}$ of ethanol and then $2 \mathrm{ml}$ of glacial acetic acid containing one drop of ferric chloride solution was added with 1 $\mathrm{ml}$ of concentrated $\mathrm{H}_{2} \mathrm{SO}_{4}$. Appearance of brown ring indicated the presence of the glycosides.

\section{Test for Alkaloids}

Crude extract $(0.01 \mathrm{~g})$ was dissolved in ethanol and was divided into two parts. Few drops of Mayer's reagent were added to one part. A creamy white precipitate indicated the presence of alkaloids. Few drops of Wagner's reagent was added to other part. A red-brown colour precipitate indicated the presence of alkaloids.

\section{Test for Phenolic Compound}

The extract was dissolved in $5 \mathrm{ml}$ of distilled water. To this, few drops of neutral $5 \%$ ferric chloride solution was added. A dark green colour indicate the presence of phenolic compound.

\section{Test for Carbohydrates}

Extract was individually dissolved in $5 \mathrm{ml}$ distilled water and filtered. The filtrates were used to test for the presence of carbohydrates.

Benedicts test: The filtrate was treated with benedict's reagent and heated gently. Orange red precipitate indicated the presence of reducing sugars.

Collection of the Diseased Plant Samples (Cabbage)

Samples of cabbage naturally infected with downy mildew were collected from Tarauni market (Tarauni L.G.A) and Na'ibawa market (Kumbotso L.G.A) in Kano state (Singh et al., 2002).

Sterilization of Apparatus and Preparation of Culture Media

All the apparatus involved in this experiment were sterilized using an autoclave machine, all the solvent also were sterilized using an oven machine.
Culture media was prepared according to the manufacturers instruction and autoclave at $121^{\circ} \mathrm{C}$ for 15 minutes. The media was amended with $0.5 \mathrm{mg}$ of streptomycin as antibiotic (Singh et al., 2002).

\section{Isolation and Identification of Fungal Isolates}

The isolation and identification technique used by Chiejni, (2008) was employed. Thin section $2 \mathrm{~mm}$ diameter) was cut from the periphery of deteriorating / diseased plant and sterilize with $1 \%$ sodium hypo chloride solution for 2 minutes. The section is rinsed in 3 changes of sterile distilled water, and plated on Potato Dextrose Agar (P.D.A) plates .The plates were then incubated at room temperature $\left(27{ }^{\circ} \mathrm{C} \pm 2^{\circ} \mathrm{C}\right)$ for seven days. The pure cultures were then obtained by several transfer of colony growth from P.D.A plates aseptically (i.e. sub-culturing to obtain axenic cultures). A small portion of fungal growth were picked carefully with aid of a pair of sterile dissecting needle and placed on a drop of lacto phenol in cotton blue on a slide covered with a cover slip. The slide under the microscope were examined first with $(\times 10)$ and then with $(\times 40)$ objective lens to observe the spores and some structures of the fungi .The fungal isolates were identified based on microscopic appearance which comprised pigmentation, colour of aerial and substrate hyphae and some kind of sexual spores.

\section{Inoculum Preparation}

The isolates were sub-cultured on Potato Dextrose Agar plates and incubated at $27{ }^{\circ} \mathrm{C} \pm 2{ }^{\circ} \mathrm{C}$. Inoculum suspension were prepared from fresh, mature (3-5 days old) cultures, in some cases an extended incubation was required for proper sporulation of the isolates, the fresh colonies were covered with $10 \mathrm{ml}$ of distilled sterile water. The conidia were rubbed carefully with a sterile cotton swab and transferred to a sterile tube (Petrikkou et al., 2001)

Preparation of Extract Concentrations for Sensitivity Test

Extract concentration of the plant material was prepared using serial dilution method as described by Aliyu and Sani (2011). Two gram (2g) of the plant extract (Senna tora) was dissolved in $2 \mathrm{ml}$ of appropriate diluent (DMSO) to arrive at $1.0 \mathrm{~g} / \mathrm{ml}$, which serves as stock solution from which appropriate quantity of Senna tora leaf extract were dissolved in $1 \mathrm{ml}$ of Dimethyl Sulphur Oxide (DMSO) to arrive at four different concentrations: 1000, 500, 250 and 125 $\mathrm{mg} / \mathrm{ml}$ respectively.

\section{Antifungal Activity/Sensitivity Test}

The extract was screened for antifungal property using the agar well diffusion technique. Potato Dextrose Agar (PDA) was used for fungal cultures. Inoculum of test fungus was spread on to sterile Potato dextrose agar plate so as to achieve a confluent growth. The plates were allowed to dry and $6 \mathrm{~mm}$ diameter wells were punched into the agar using a sterile cork borer and filled with plant extracts of different concentration. A standard antibiotic (Mancozeb, concentration $1 \mathrm{~g} / \mathrm{ml}$ ) was used as standard and Dimethyl Sulphoxide (DMSO) as negative control. The fungal plates were incubated for 72 hours at $37^{\circ} \mathrm{C}$. 
The degree of sensitivity was determined by observing and measuring the diameter in millimeter $(\mathrm{mm})$ of the visible zone of inhibition of the microbial growth produced by the diffusion of the extracts (Stockes and Ridgeway, 1980).

\section{Determination of Minimum Inhibitory Concentration (MIC) and Minimum Fungicidal Concentration (MFC)}

The minimum inhibitory concentration for antifungal activity of Senna tora leaf extract by broth dilution technique. Sabourauds Dextrose Broth was prepared and poured $10 \mathrm{ml}$ each in the set of six test tube. The tubes were then sterilized by autoclave. The different volumes of this extract was delivered accurately to each test tube using sterile pipette and thoroughly mixed to obtain the concentrations as $(500 \mathrm{mg} / \mathrm{ml}$, $250 \mathrm{mg} / \mathrm{ml}, 125 \mathrm{mg} / \mathrm{ml}, 62.50 \mathrm{mg} / \mathrm{ml}$ ).

The tubes were then inoculated with $0.05 \mathrm{ml}$ of the standardised inoculum / fungal culture. The inoculated tubes were incubated at temperature $30^{\circ} \mathrm{C}$ - $32^{\circ} \mathrm{C}$ and observed for growth by monitoring the turbidity produced. The test procedure was repeated to check the reproducibility of the results. The lowest concentration that inhibits the growth is minimum inhibitory concentration (MIC).

The minimum fungicidal concentration (MFC) was determined by sub-culturing from each well showing no apparent growth. Least concentration of extract showing no visible growth on sub-culturing was taken as MFC (Basri and Fan,2005).

\section{RESULTS}

The result showed that the extracts yielded $13.2 \mathrm{~g}$. The aqueous leaf extract was found to be dark green in colour. The texture of the extract was gummy with pungent smell and is soluble in DMSO as shown in Table 1.

Results of phytochemical screening of aqueous leaf extracts indicate the presence of some secondary metabolites such as alkaloid, tannins, flavonoids, glycosides, saponins, carbohydrates, with absence of phenolic compounds as shown in Table 2.

Perenospora parasitica, Rhizopus spp, and Aspergillus niger were isolated from diseased cabbage. Perenospora parasitica is the pathogen causing downy mildew of cabbage and it was found to be predominant pathogen causing downy mildew (Table 3).

Generally, the zone of inhibition increased with increase in concentration of extract as shown in Table 4. Bioassay study showed that the extract of Sennatora was more active at concentration of $1,000,000$ on Perenospora parasitica which compares favourably with the standard Mancozeb $(20 \mathrm{~mm})$ each. No activity against Perenospora parasitica was observed at 125 and $250 \mathrm{mg} / \mathrm{ml}$. Similarly, the negative control (DMSO) showed no zone of inhibition.

Results of Minimum Inhibitory Concentration (MIC) shows that the aqueous leaf extract of Senna tora against Perenospora parasitica at 500 and $250 \mathrm{mg} / \mathrm{ml}$ showed no visible growth of microorganism in the test tube after incubation while turbidity was observed within the other test tubes containing the remaining concentrates of 125 and $62.50 \mathrm{mg} / \mathrm{ml}$ as shown in Table 5.

Result of MFC showed that the minimum inhibitory concentration value is fungistatic

Table 1: Physical Characteristics of Aqueous Leaf Extract of Senna tora

\begin{tabular}{ll}
\hline Plant part & Leaves \\
\hline Solvent & Distilled water \\
Weight & $13.2 \mathrm{~g}$ \\
Colour & Dark green \\
Odour & Pungent \\
Texture & Gummy \\
Solubility in DMSO & Soluble \\
\hline
\end{tabular}

Table 2: Phytochemical Constituents of Aqueous Leaf Extract of Senna tora

\begin{tabular}{lll}
\hline Phytochemical constituents & aqueous extract & \\
\hline Tannins & + & \\
Saponins & + & \\
Carbohydrates & + & \\
Glycosides & + & \\
Alkaloids & + & \\
Phenolic compounds & + & \\
Flavonoids & & \% occurrence \\
\hline KEYS: Present $=+$, Absent $=$ - & & 70 \\
Table 3: Frequency of occurrence of the isolates & Frequency & 20 \\
\hline Isolates & 7 & 10 \\
\hline Perenospora parasitica & 2 & \\
Rhizopus spp & 1 & \\
Aspergillus niger & &
\end{tabular}


Table 4: Anti-Fungal Activities of Aqueous Leaf Extract of Senna tora on downy mildew disease of cabbage (Perenospora parasitica)

\begin{tabular}{ll}
\hline Concentrations $(\mathbf{m g} / \mathbf{m l})$ & Zone of Inhibition $\mathbf{( m m})$ \\
\hline 125 & 0 \\
250 & 0 \\
500 & 15 \\
1000 & 20 \\
Standard (Mancozeb) & 20 \\
DMSO & $\underline{0}$ \\
\hline
\end{tabular}

Table 5: Minimum Inhibitory Concentration (MIC) of Aqueous Leaf Extracts of Senna tora Concentrations $(\mathbf{m g} / \mathbf{m l})$

\subsection{0}

125

250

500

Positive control

Negative control Turbidity signs

KEYS: Turbidity Present $=+$, Turbidity Absent $=$

\section{DISCUSSION}

The result of phytochemical analysis of aqueous leaf extract of Senna tora indicated the presence of Tannin, Saponins, Carbohydrate, Glycoside, Akaloids and Flavonoids. This was in consonance with work of Akindahunsi and Olaleye (2003). Some of the metabolites have been reported to be responsible for antimicrobial activity in some ethnomedicinal plants (Kumar et al., 2009 ${ }^{\mathrm{a}}$ ).

Reports in other studies by Linn et al. (1979) on phytochemical screening revealed the presence of certain plant metabolites, which have been known to elicit inhibitory effect on microorganisms. These phytochemicals may have caused the observed inhibitory effect either singly or in synergy with each other, this requires further investigation. Also, ReyesChilpa et al. (2009), reported that Flavonoids possess antifungal property. Earlier, Baba-Moussa et al. (1999) reported that Tannins present in some plant species possess antifungal property. It is hoped that the elucidation of the structure of the active principle(s) and its/their subsequent use in antifungal investigations would give better results.

Tannins also interfere with cell division hence the presence of tannins in Senna tora could account for the antimicrobial activity in the study, this is in agreement with the findings of Chewonarin et al. (1999). Tannins have been traditionally used for protection of inflamed surface of the mouth and treatment of catarrh, wound and diarrhea.

It was observed that the fungal isolates used in this research exhibited varying degrees of susceptibility to the extracts. Thus, the values obtained for the zones of inhibition differed, for test organism. These results corroborate the findings of Anani et al. (2000) and Rajakaruna et al. (2002). Results of this study also agree with the report of Kumar et al. $\left(2009^{\mathrm{b}}\right)$. The difference in susceptibility observed in this study could be attributed to the inherent resistance factor of the test organisms among other factors (Ekpo and Etim, 2009).

The result showed that the MIC of Perenospora parasitica is $250 \mathrm{mg} / \mathrm{ml}$ the antifungal activities observed could be due to the presence of secondary
$+$

$+$

$-$ metabolites which have been reported as active constituents responsible for antifungal activities (Salihu and Garba, 2008).

\section{CONCLUSION}

Observations and data collected in the study indicated that fungal species identified to be associated with the diseased symptoms of Downy mildew of Cabbage (Brassicca olaraceae) were Peronospora parasitica, Rhizopus spp and Aspergillus niger. The predominant species identified was Peronospora parasitica and therefore suspected to be the causal agents of the disease symptoms observed on the cabbage plants in the study areas.

The aqueous leaf extract of Senna tora is effective or shown good inhibitory activity against Perenospora parasitica as compared with standard Mancozeb which is an indication that the parts of plant contain some major bioactive compounds that inhibited the growth of the microorganism thereby proving cheap and effective source of derived drugs.

\section{Recommendations}

Attempts should be made to conduct in vivo studies with the extracts (such as toxicity of the plant to humans at different concentration is very essential in the use of the plant for treatment and the efficacies of the different concentrations in the in vivo control of Downy mildew of Cabbage) so as to confirm the present in vitro findings.

Further experimental and clinical trials need to be carried out on the individual isolates or fraction of the aqueous extract of Senna tora leaves. This would also help to correlate the antifungal activity with known constituents of Senna tora leaves.

\section{REFERENCES}

Akindahunsi, A.A and Olaleye, M.T (2003). Toxicological investigation of aqeous and methanolic extract of Hibiscus sabdariffa L. $J$ Ethnopharmacol 89, Pp161-104

Aliyu, B.S, and Sani, H. D (2011). In-vitro antibacterial activity of Anogeissus leiocarpus (stem bark) extracts against Escherichia coli and Staphylococcus aureus. Bayero Journal of Pure and Applied Sciences, 4(2): 56 - 59 
Anani, K. Hudson, J.B.Desouza. C, Akpagana, K. Lower, G.H.N., Amason, J. T and Gabeassor, M. (2000). Investigation on Medicinal Plants of Togo for Antiviral and Antimicrobial Activities. Pharm. Biol., 38: 40-45.

Baba-Moussa, F.,Akpagana, K. and Bouchet, P. (1999). Antifungal Activities of Seven West African Combretaceae used in Traditional Medicine. J. Ethnopharm., 66(3): 335-338.

Basri, D.F., and Fan, S.H.(2005). The potential of aqueous and acetone extracts of galls of Quercus infectoria as antibacterial agents. India, J pharmaco/37(1): 26-29.

Benzie, F.F and Strain, J.J. (1996). The Ferric Reducing Ability of Plasma [FRAP] As A Measure of "Antioxidant Pouer". The FRAP Assay. Analytical Biochemistry, 239: 70-76.

Bonjar, Gills and P.R, Farrokhi., Antimicrobial Activity. Planta Medica, 36: 311-321.J. Nat. Med., 2004, 8, 34.

Chewonarin, T. Kinouchi, H., and Arimochi, T. (1999). Effect of roselle. A thai medicinal plant on the mutagenicity of various known mutation in Somonrlle pyphimurium 37(6): 591-601

Chiejni N.A (2008). Mycoflora of some salad vegetables, Bio- research 6(2): 392-395.

Ekpo MA, Etim PC (2009). Antimicrobial activity of ethanolic and aqueous extracts of Sidaacuta on microorganisms from skin infections. $J$. Med. Plants Res., 3(9): 621-64.

Harborne, J.B (1973). Phytochemical methods. Chapman and hall, Ltd, London, Pp49-188.

Kumar A, Hauarasan., R. jayachandran and T., Nondkishman $\left(2009^{\mathrm{a}}\right)$ : Phytochemical investigation on a tropical plant, Syzgium cumini from tamilnadu. Journal of nutrition 8(1):83-85.

Kumar, A., Hauarasan, R..Jayachandran, T., and N. Kishman $\left(2009^{b}\right)$ : Phytochemical investigation on a tropical plant ,Syzgium cumini from tamilnadu. Journal of nutrition 8(1):83-85.

Kunle O.F and Egharevba, H.O (2009). Preliminary studies on Vernonia ambigua: Phytochemistry studies and antimicrobial screening of the whole plant. Ethnobotanical leaflets 13: 1216-21
Linn, M.T. Kitajima, N and Costa, R (1979) Properties Of A Possible Carlavirus From Cerrado Native Plant. Cassia sy/vestris Plant Diseases Report, 6, 501-505.

Maity TK, Mandal SC, Mukharjee P.K and Saha, K. (1998). Studies On Anti-Inflammatory Effect Of Cassia tora Leaf Extract, Phytother Res, 12(3), 221-223.

Palanichamy S., Nagarajan S., (1990). Antifungal activity of cassia alata leaf extract. $J$. ethnopharmacoyl 1990: 29: 337-340.

Petrikkou, E., Rodriquez, J.L, M., Gomez.(2001). Inoculum standardization for antifungal susceptibility testing on filamentous fungi. Journal of clinical microbiology 39, 1345-7.

Rai, M. Acharya, D. and Wadegaonkar, P. (2003).Plant derived antimycotics. Current trends and future prospects. Hart-worth Press. NY Pp 95-165

Rajakaruna N, Haris CS, Towers GHN (2002). Antimicrobal activity of plants collected from serpentine outcrops in Sri Lanka. Pharm. Biol., 40: 235-244.

Reyes-Chilpa, G., Moreno, T., Jimenez, E and Quiroz, V. (2009). Flavonoids and Isoflavonoids with Antifungal properties from Platymiscium yucatanum heartwood Holzforschuna. Inter. J. Biol. Chem. Phys. Tech. Wood., p. 52.

Salihu, L and Garba, S (2008): Medical laboratory of the broachille constituents of some medicinal plants. 164-168.

Singh B, Sahu PM, Sharma MK, 2002. Anti-inflamatory and antimicrobial activities of triterpenoids from Strobilanthes callosus Nees. Phytomedicine, 9: 355- 359.

Sofowora, A.A. (1993). Medicinal plants and Traditional Medicines in Africa. Spectrum Books Ltd,Ibadan, Nigeria.2: 81-85.

Stocks, J.E. and Ridgeway, G. I. (1980). Sensitivity testing techniques in clinical laboratory, 5th edition Edward Arnold publishers, UK Pp 320.

Trease, G.E. and Evans, W.C. (1989). Pharmacognosy .11th Edition Brailliar Tridel can. Macmillan publishers. UK Pp 20-25. 